\title{
O SER ENFERMEIRO NUM CONTEXTO TRANSCULTURAL
}

\author{
THE NURSE-BEING IN A TRANSCULTURAL CONTEXT
}

\author{
Maria de Magdala Nóbrega ${ }^{1}$ \\ David Lopes Neto ${ }^{2}$ \\ Herbert Figueiredo Dantas ${ }^{3}$ \\ Vera Lúcia de Almeida Becerra Perez ${ }^{4}$
}

RESUMO: Estudo exploratório-descritivo, desenvolvido numa abordagem qualitativa, objetivando conhecer como os enfermeiros do sexo masculino percebem a questão do preconceito e do estigma da família, dos colegas de profissão e, ainda, a visão êmica destes sobre o referido problema. A pesquisa foi realizada com mestrandos do sexo masculino do Curso de Mestrado em Enfermagem de Saúde Pública, da Universidade Federal da Paraíba. A população foi de seis enfermeiros, sendo a amostra constituída de quatro enfermeiros. Os dados foram coletados através de um questionário com perguntas abertas, baseadas na Teoria Transcultural de Leininger. Os resultados foram gerados na forma de palavras e analisados em termos de grupos de respostas similares. A conclusão do estudo retrata o choque e a imposição cultural aos trabalhadores masculinos da enfermagem, os quais, ao longo dos anos, têm sofrido diferenciações preconceituosas e estigmatizantes de diferentes atores sociais.

UNITERMOS: Enfermagem transcultural - Profissão de enfermagem Preconceito - Estigma.

${ }^{1}$ Enfermeira Assistente da Secretaria de Estado da Saúde da Paraíba > Aluna do Curso de Mestrado em Enfermagem. CCS/UFPB.

2 Docente da Escola de Enfermagem de Manaus. Aluno do Curso de Mestrado em Enfermagem. CCS/UFPB.

${ }^{3}$ Enfermeiro Assistente da Secretaria Municipal de Saúde de Manaus. Aluno do Curso de Mestrado em Enfermagem. CCS/UFPB.

${ }^{4}$ Professora Adjunto do Departamento de Enfermagem de Saúde Pública e Psiquiatria e do Mestrado em Enfermagem. CCS/UFPB. 


\section{INTRODUÇÃO}

Nas três últimas décadas o mundo vem atravessando constantes transformações que ultrapassam a capacidade imediata do homem de interpretar todos os problemas decorrentes dessas mudanças (Drucker' ${ }^{\prime}$ ). A sociedade moderna conquistou um complexo de normas, valores e comportamentos que, conjuntamente, com a ciência e a tecnologia modificaram o pensamento e as crenças do homem contemporâneo.

A área da saúde tem alcançado resultados exitosos através de pesquisas que se realizam diretamente voltadas para o desenvolvimento de novos conhecimentos. A enfermagem vem acompanhando este desenvolvimento científico dando total conhecimento aos problemas existentes e às suas possiveis soluções, buscando, principalmente, o reconhecimento da profissão pela sociedade.

A enfermagem, mesmo sendo uma profissão de vital importância e conhecida dentro e fora dos limites das instituições de saúde, ainda é pouco valorizada pela sociedade por vários fatores que interferem também na prática e na organização das suas diferentes categorias, tais como: força de trabalho predominantemente feminina, caracterizando o preconceito da questão de gênero; estratificação da classe em categorias, fragmentando $o$ poder da profissão e a baixa remuneração, reproduzindo a ideologia capitalista de utilização de mão-de-obra mais barata.

Com a reflexão acima e com base nos conceitos da Teoria Transcultural Teoria da Diversidade e Universidade Cultural do Cuidado - de Madeleine Leininger, tenta-se, neste estudo, conhecer como os enfermeiros do sexo masculino percebem a questão do preconceito e do estigma da família, dos colegas de profissão quanto a estes serem enfermeiros e, ainda, a visão êmica destes sobre esta problemática.

\section{MARCO TEÓRICO}

O conceito de enfermagem transcultural é relativamente novo na literatura de enfermagem. A necessidade de incorporar o cuidado cultural à prática clínica tem levado os enfermeiros, nessas três últimas décadas de mirabolantes mudanças, a reconhecerem efetivamente o cliente e a si mesmo em sua totalidade.

Leininger ${ }^{5}$ define enfermagem transcultural como uma área maior da enfermagem que focaliza um estudo comparativo e analítico das diferentes culturas e subculturas no mundo, com respeito às condutas de cuidados dos enfermeiros, o cuidado de enfermagem, os valores do processo saúde-doença, 
as crenças e os padrões de comportamento com o objetivo de desenvolver um corpo de conhecimento científico e humanístico, visando prover uma cultura específica e uma prática de cuidado de cultura universal de enfermagem.

A pesquisa tomou como fundamento a Teoria Transcultural, a qual permite $o$ entendimento de como os indivíduos percebem o seu mundo ou universo e nele inserem suas perspectivas de vida George $e^{3}$. O presente estudo, por trabalhar a saúde mental do trabalhador de enfermagem pelo prisma do preconceito cultural e do estigma, contempla as seguintes definições da Teoria Transcultural:

CULTURA - São valores, crenças, normas e práticas de vida de um determinado grupo, aprendidos, partilhados e transmitidos, que orientam o pensamento, as decisões e as ações de maneiras padronizadas.

VISÃO DE MUNDO - É a maneira pela qual as pessoas olham o mundo ou universo.

ESTRUTURA SOCIAL - É a natureza dinâmica dos fatores estruturais ou organizacionais inter-relacionados de uma determinada cultura ou sociedade e a maneira como funcionam esses fatores para dar sentido e ordem cultural, incluindo fatores religiosos, políticos, econômicos, educacionais, tecnológicos, familiares e culturais.

CONTEXTO AMBIENTAL - É a totalidade de um acontecimento, situação ou experiência particular que confere sentido às expressões humanas, incluindo interações sociais, dimensões físicas, ecológicas, emocionais e culturais.

IMPOSIÇÃO CULTURAL - São esforços sutis ou não para impor valores, crenças e comportamentos culturais a um individuo, família ou grupo.

Leininger ${ }^{6}$, estudando o cuidado como essência da enfermagem, assinala a necessidade de constante clarificação dessas definições que formam o arcabouço de sua teoria.

Gualda, citada por Pamplona \& Parada ${ }^{8}$, afirma que a própria Leininger, ao considerar a sua teoria como "aberta" e "inacabada", está em incessante aprimoramento das suas definições e conceitos, questionando a pertinência epistemológica dos termos por ela empregados, com o fito de "descobrir a essência e os atributos do cuidado numa perspectiva cultural".

Esquematicamente, a Teoria Transcultural é representada no Modelo Sunrise, o qual é subdividido em quatro niveis que retratam as dimensões de Diversidade e Universalidade Cultural do Cuidado. Este modelo, numa visão simbólica, significa a descoberta do cuidado a ser prestado aos clientes (indivíduos, famílias, grupos e instituições), considerando as várias culturas nas quais estes se encontram inseridos. 
A teorista, visando um maior aprofundamento e ampliação do conhecimento das características da sua teoria, descreveu como pressupostos maiores:

1. O cuidado humano é um fenômeno universal, mas as expressões, o processo, as formas e os padrões de cuidar variam entre as culturas;

2. As ações do cuidado são primordiais desde o nascimento, desenvolvimento, crescimento e sobrevivência dos seres humanos até a morte;

3. O cuidados aos indivíduos de diversificadas culturas é a essência da enfermagem transcultural;

4. A enfermagem é uma profissão que envolve um cuidado cultural lógico e coerente por prestar esse cuidado aos diferentes povos que formam o contingente populacional do mundo;

5. As condutas ao cuidar, os objetivos e as funções do enfermeiro variam culturalmente porque a estrutura social, a visão de mundo e os valores culturais das pessoas diferem culturalmente;

6. O cuidado é largamente cultural e requer uma base de conhecimento cultural e habilidade para satisfazer a eficácia da prática de enfermagem;

7. O cuidado é a essência da enfermagem e uma natureza distinta, dominante e única da enfermagem;

8. O cuidado tem uma dimensão cultural biofísica, psicológica, social e ambiental;

9. A enfermagem é um fenômeno transcultural quando os enfermeiros interagem com os clientes, com os colegas de profissão e com outros grupos e requer que os enfermeiros identifiquem e usem 0 processo interpessoal enfermeiro-cliente e um sistema de dados que facilite este processo;

10. A cura pode ocorrer sem o cuidado, mas o cuidado não pode ocorrer sem a cura.

Com estas premissas básicas, Leininger tem desenvolvido muitas formulações para a sua teoria como exemplos estimuladores de futuras pesquisas baseadas em investigações antropológicas na enfermagem.

O estudo é desenvolvido mediante a apresentação de duas variáveis - o preconceito e o estigma. $O$ termo preconceito tem um amplo significado que se inter-relaciona com os pressupostos teóricos de Leininger. Para Ferreira ${ }^{2}$, o preconceito é toda idéia preconcebida, fato suspeito, intolerância ou aversão praticada por qualquer pessoa em relação às raças, aos credos, às religiões, aos comportamentos, às profissões, ao gênerc. 
$\mathrm{Na}$ enfermagem, o preconceito contra o profissional do sexo masculino existe e vincula-se ao ato discriminatório que ainda persiste arraigado na sociedade. Esta discriminação permeia, principalmente, o âmbito familiar e o ambiente de trabalho, proporcionando aos enfermeiros homens uma situação deslocamento, desencanto e estigmatização.

O estigma é definido por Ferreira ${ }^{2}$ como sendo uma cicatriz ou sinal de censura ou condenação a um indivíduo e decorre do tratamento preconceituoso dado a certas categorias sociais, raciais, profissionais.

\section{METODOLOGIA}

Trata-se de um estudo qualitativo, exploratório-descritivo, envolvendo os pressupostos especificos sobre a realidade e as formas particulares de coleta e apresentação de dados que fazem parte de um estudo etnográfico. A pesquisa foi realizada com mestrandos do sexo masculino, do Curso de Mestrado em Enfermagem de Saúde Pública, da Universidade Federal da Paraiba, matriculados nos períodos 94.1 e 95.1, objetivando conhecer a percepção destes quanto à inserção na enfermagem e como estes percebem os preconceitos e os estigmas advindos das suas famílias e dos colegas de profissão.

Foi realizado um contato prévio com os enfermeiros que participariam do estudo, sendo-lhes explicado os objetivos, a importância e a contribuição do estudo para a academia, a sociedade e para a enfermagem. Da população de seis mestrandos, foi trabalhada uma amostra de quatro, tendo em vista que apenas estes concordaram em participar do estudo e por estarem os outros dois participando da pesquisa na qualidade de pesquisador.

Para a coleta de dados utilizou-se um instrumento do tipo questionário, com perguntas abertas e baseadas na Teoria Transcultural de Leininger. Os dados foram coletados no período de 03 a 07 de junho de 1995, mediante a interação dos pesquisadores com os pesquisados. Os resultados foram gerados na forma de palavras e analisados em termos de grupos de respostas similares por melhor expressarem a percepção dos termos preconceito e estigma pelo grupo pesquisado.

\section{ANÁLISE E DISCUSSÃO DOS RESULTADOS}

Os quatro enfermeiros que participaram do estudo têm entre 3 e 15 anos de formados e trabalham nas áreas de assistência e docência. A primeira questão - 
sobre o tempo que os mesmos têm de formado - foi elaborada com a finalidade de conhecer suas vivências em anos, fato este que contribuiu substancialmente ao considerarmos que esta variável leva a uma maior visão de mundo a partir da prática de enfermagem no campo profissional.

Quando indagados se percebiam algum preconceito advindo das suas próprias familias, apresentaram como resposta unânime a existência do preconceito no seio familiar, pois para eles a enfermagem desde os primórdios é considerada uma profissão predominantemente feminina. Mas este preconceito decresce em grau quando comparado com o preconceito de um grupo maior (comunidade), tendo em vista que na família o fator tempo interfere positivamente no reconhecimento de que a enfermagem gera uma maior renda familiar (aspecto social e econômico) e é considerada uma profissão digna e vocacional (aspectos de valorização). Estes pensamentos expressam a imposição cultural da família que a evidencia muito mais ao questionar: porquê não ser médico?

O questionamento sobre a existência de preconceito e de estigma por parte dos colegas de profissão quanto à inserção do homem na enfermagem também obteve a unanimidade do grupo em afirmar que há uma forte pressão preconceituosa, inclusive com relato de que por parte das enfermeiras o preconceito é mais evidente, correlacionando o ser enfermeiro com a questão de gênero. Afirmaram, também, não terem tido maiores problemas por causa da diferenciação pelas quais passaram. Apenas um deles declarou um problema de ordem de relacionamento, mas que para ele foi solucionado pela sua permuta do quadro assistencial para o docente, situação esta denominado pelo enfermeiro de superação do problema. Esta negação da diversidade cultural do enfermeiro pelo enfermeiro está claramente explícita nos pressupostos teóricos de Leininger ${ }^{7}$, os quais descrevem que a enfermagem é um fenômeno transcultural quando o enfermeiro interage com o próprio enfermeiro, pois, quando não há esta interação, os fatos evidenciam discrepâncias à não visualização de todas as pessoas pelos enfermeiros, inclusive deles próprios, como possuidores de uma cultura, de uma herança cultural e de uma diversidade cultural construida ao longo dos anos. Estas discrepâncias espelham as diferenças, trabalhadas neste estudo, sob as terminologias - preconceito e estigma.

Para Porter ${ }^{9}$, o trabalho da enfermagem não é exclusivamente de domínio feminino, pois os homens são capazes de cuidar e de ajudar pessoas. Logo, eles são capazes de ser enfermeiros. Neste sentido, tanto preconceito quanto estigma são situações antiquadas para o cenário pós-moderno. 
A quarta e última questão - Como você se sente como enfermeiro? proporcionou diversificações de opiniões entre os pesquisados. As mais evidentes foram:

Sinto-me bem na profissão, provém falta mais credibilidade por parte das pessoas quanto as enfermeiro do sexo masculino quando da realizaçäo de suas açôes, pois elas visualizam apenas a lado do sexo e não a figura do profissional."

Sou frustrado com essa desigualdade cultural e estigmatizadora em relação ao sexo e ao trabalho. Nlas creio que seja pelo subdesenvolvimento do pais, a qual carreia problemas como a analfabetismo, a pobrera, a negaçäo dos valores sociais e a desualorizaçäo profissional. Porém, esta condenação da sociedade é frustrante!."

"A enfermagem é a minha segunda casa. É nela que eu encontro a meu sustento e me vealizo profissionalmente. Sei que existem preconceitos, estigmas, tabus e discriminação. Mas a importante é a modo como a profissional desenvolve a seu trabalho, pois é a partir dele que vem o reconhecimento.

"Eu me sinto muito bem dentro da minha profissão. Encontrei alguns problemas, ou melhor, preconceitos, mas passaram desapercebidos com o passar do tempo. Al realidade é que a enfermagem precisa ser considerada ciência e não ser jullgada por questäa de gênero.

Ao final desta análise podemos afirmar que o grupo estudado percebe a existência do preconceito em todo o seu contexto ambiental, que os enfermeiros assistenciais não se sentem bem no ambiente de trabalho e que, em algumas situações, se sentem deslocados e estigmatizados pelo fato de serem enfermeiros. 


\section{ANÁLISE CONTEXTUAL QUALITATIVA DAS RESPOSTAS À LUZ DO MODELO SUNRISE DE LEININGER - TEORIA TRANSCULTURAL}

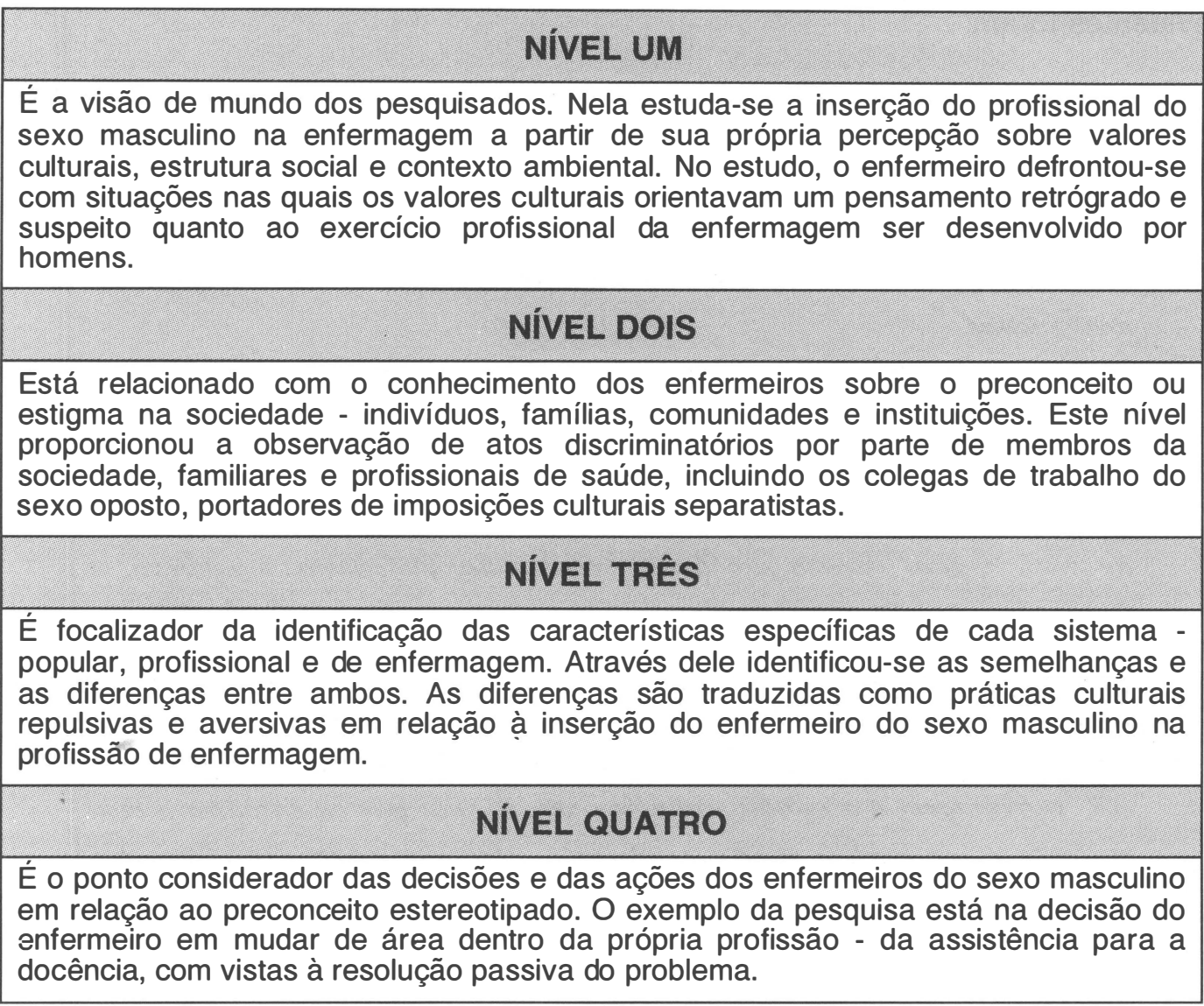

\section{CONSIDERAÇÕES FINAIS}

Historicamente, o estabelecimento da enfermagem moderna, a partir da organização do trabalho por Florence Nightingale, proporcionou à enfermagem uma estabilização científica e a superação da pressão e da segregação social com barreiras preconceituosas e de exclusão de pessoas que têm a vocação de ser enfermeiro, (Halloran $\left.{ }^{4}\right)$. Com isso, grupos da sociedade contemporânea no mundo inteiro vêm tentando quebrar as regras e as normas obsoletas de preconceitos e estigmas que envolvem o binômio gênero-trabalho.

Os homens, assim como as mulheres, têm sido vítimas desses preconceitos e estigmas quando das suas investiduras em profissões supostamente femininas - telefonistas, assistentes sociais, faxineiros, bibliotecários e enfermagem. O preconceito perpassou o orbe tolerável do desconhecimento e passou a ser produto de uma cultura constituída de idéias preconcebidas e divergentes da realidade. 
Em síntese, o estudo retrata o choque e a imposição cultural aos trabalhadores masculinos da enfermagem, onde estes, ao longo dos anos, têm sofrido diferenciações preconceituosas e estigmatizantes de diferentes atores sociais. Contudo, enfermeiros do sexo masculino podem não ser as respostas para todos os problemas da profissão de enfermagem, mas a presença deles em maior número pode ser bem um barômetro de valor econômico e social para a enfermagem. Afinal, homens e mulheres podem contribuir igualitariamente com a valorização desta ciência, construindo uma profissão diferente, na qual o potencial técnico-científico seja a essência do profissional - ser humano - e este possa desenvolver as suas intervenções com eficiência e eficácia.

ABSTRACT: This is a descriptive and exploratory study developed according to a qualitative approach, aiming at discovering how male nurses are seen by the family and other professionals regarding their profession. Also, it has observed their technical vision about this problem. This research was done with male nurses from the Master Degree Course in Public Health Nursing at the Federal University of Paraiba. The population of this study was composed of six male nurses from which four agreed in taking part in this research. The data were collected through a questionnaire with open questions, based on the Leininger Transcultural Theory. The results showed that a great shock and cultural impositions among the male nurses, who have suffered a great variety of misconceptions and stigmatized assumptions from different social actors.

KEYWORDS: Transcultural nursing - Nursing profession - Prejudice - Stigma.

\section{REFERÊNCIAS BIBLIOGRÁFICAS}

1. DRUCKER, Peter F. Administrando para o futuro: os anos 90 e avirada do século. 3. ed. São Paulo: Pioneira, 1992. p.01.

2. FERREIRA, Aurélio B. de Holanda. Minidicionário da língua portuguesa. 3. ed. Rio de Janeiro: Nova Fronteira, 1993, p. 231,292,437.

3. GEORGE, Julia B.; Madeleine Leininger. In: GEORGE, J. B. Teorias de enfermagem: os fundamentos para a prática profissional. Porto Alegre: Artes Médicas, 1993. p. 286-289.

4. HALLORAN, Edward J. Men in nursing. In: McCLOSKEY J. C. \& GRACE, H. K. Current issues in nursing. Saint Louis: Mosby Company, 1990. p. 547-555.

5. LEININGER, Madeleine. Transcultural nursing: concepts, theories, and pratices. New York: John Willeys \& Sons, 1978. 
6. Care: The essence of nursing and health. Thorofare: Slack, 1984. p. 3-8.

7. Cultural diversities of health and nursing care. In: SEXTON, D. The nursing clinics of North America: cultural and biological diversity and health care. Philadelphia: WB Saunders, 1977. p. 5-18.

8. PAMPLONA, Vera Lúcia; PARADA, Cristina Maria Garcia de Lima. Pesquisa etnográfica em enfermagem: uma aproximação. R. Bras. Enferm. Brasília, v.47, n.3, p.219-230, jul./set., 1994.

9. PORTER, Sam. Men researching woman working. Nursing Outlook, v.44, n.1, p.22-26, jan./feb., 1996. 